\title{
A história de pessoas com obesidade mórbida: uma experiência no sul do Brasil
}

Aceito para publicação em junho de 2010

Alixandra Trindade dos Santos ${ }^{1}$ Cintia Hugen Panata ${ }^{2}$ Janaina Schmitt ${ }^{3}$ Maria Itayra Padilha ${ }^{4}$ Lucia Nazareth Amante ${ }^{5}$

Este estudo objetiva conhecer a história de vida de clientes com obesidade mórbida internados em um hospital geral para submeterem-se à cirurgia bariátrica. Pesquisa qualitativa descritiva por meio de entrevistas, abordando a história de vida de dez sujeitos, cujos resultados apontaram dificuldades para o autocuidado que se evidenciaram pela desistência da prática de atividades físicas e consequente dor corporal. A sexualidade aparentemente não é um fator importante, porém o preconceito faz parte do cotidiano do indivíduo obeso, interferindo em sua vida, atitudes e decisões. A autoimagem negativa motiva a realização da cirurgia bariátrica. Os discursos revelaram o desconhecimento quanto à doença e à cirurgia e a importância do papel da equipe de saúde.

Descritores: História, Obesidade, Obesidade Mórbida, Cirurgia Bariátrica.

\section{The history of people with morbid obesity: experience in southern Brazil}

This study aims to examine the history of life of patients with morbid obesity hospitalized in a general hospital to undergo bariatric surgery. Descriptive qualitative research by means of interviews, approaching the life history of 10 subjects, whose results indicated difficulties for self-care that is evidenced by the withdrawal of physical activity and consequent body pain. Sexuality is apparently not an important factor, but the bias is part of daily life in obese individuals, interfering in his life, attitudes and decisions. . The negative self-image motivates the bariatric surgery. The speeches revealed ignorance about the disease and surgery and the importance of the role of the health team.

Descriptors: History, Obesity, Morbid Obesity, Bariatric Surgery.

\section{La historia de las personas con obesidad mórbida: experiencia en el sur de Brasil}

Este estudio tiene como objetivo examinar la historia de vida de los pacientes con obesidad mórbida, hospitalizados en un hospital general de someterse a cirugía bariátrica. La investigación descriptiva cualitativa a través de entrevistas, que trata de la historia de vida de 10 sujetos, cuyos resultados indicaron dificultades para el autocuidado que se evidencia por el retiro de la actividad física y dolor corporal consecuente. La sexualidad no es al parecer un factor importante, pero el sesgo es parte de la vida diaria en personas obesas, lo que interfiere en su vida, las actitudes y decisiones. La imagen negativa de sí mismo fomenta la cirugía bariátrica. Los discursos revelaron la ignorancia sobre la enfermedad y la cirugía y la importancia del papel del equipo de salud.

Descriptores: Historia, Obesidad, Obesidad Mórbida, La Cirugía Bariátrica.

\section{INTRODUÇÃO}

A obesidade mórbida é uma doença crônica caracterizada pelo acúmulo excessivo de tecido adiposo no organismo. É considerada uma doença epidêmica em vários países. Multifatorial, de origem genética e metabólica, é agravada pela exposição a fenômenos ambientais, culturais, sociais e econômicos, associados a fatores demográficos (sexo, idade, raça) e ao sedentarismo ${ }^{(1)}$. Com a transição para a urbanização e industrialização, houve um crescimento no consumo de alimentos industrializados, aumentando assim o consumo de energia das necessidades do corpo. Com isso, ocorre o ganho de peso, ocasionando a obesidade, que constitui um fator de risco para doenças crônicas não

1 Acadêmica do curso de graduação em enfermagem da Universidade Federal de Santa Catarina. E-mail: alixandra.trindade@hotmail.com.

2 Acadêmica do curso de graduação em enfermagem da Universidade Federal de Santa Catarina.

3 Acadêmica do curso de graduação em enfermagem da Universidade Federal de Santa Catarina.

4 Professora associada do departamento de enfermagem da UFSC. Doutora em enfermagem pela Escola Anna Nery (UFRJ). Pós-doutora pela Lawrence Bloomberg Faculty of Nursing na University of Toronto, Canadá. Líder do Grupo de Estudos da História do Conhecimento de Enfermagem e Saúde (Gehces). Pesquisadora do CNPq.

5 Professora adjunta II do departamento de enfermagem da UFSC. Doutora em enfermagem. Integrante do Grupo de Estudos da História do Conhecimento em Enfermagem e Saúde (Gehces) e do Núcleo de Pesquisas em Neurologia Experimental e Clínica do HU - UFSC. 
transmissíveis. Essas compõem um grupo de entidades que se caracterizam por apresentar longo período de latência, tempo de evolução prolongado, lesões irreversíveis e complicações que acarretam graus variáveis de incapacidade ou óbito ${ }^{(2)}$. Os hábitos alimentares desenvolvidos no século 21 são marcados pela forte presença de carboidratos e, principalmente, de lipídios na dieta, determinantes para o aumento da incidência da obesidade ${ }^{(3)}$. Os hábitos alimentares na infância têm sido um importante fator para o desenvolvimento da obesidade, tanto na infância quanto na maturidade. A família é a primeira instituição que tem ação sobre os hábitos do indivíduo, sendo responsável pela compra e pelo preparo dos alimentos em casa, transmitindo seus hábitos aos filhos. A qualidade de vida de portadores de obesidade mórbida é comprometida devido a prejuízos psicossociais e às disfunções físicas, como dores nas articulações e na coluna, que impossibilitam atividades do dia a dia ${ }^{(4)}$. Como a obesidade é uma doença crônica de etiologia multifatorial, seu tratamento envolve vários tipos de abordagens: orientação dietética, programação de atividade física e uso de fármacos antiobesidade são os mais recomendados. Quando esses métodos não são eficazes, surge a necessidade de uma intervenção cirúrgica - a gastroplastia. O objetivo deste estudo foi conhecer a história dos pacientes que se submetem à cirurgia bariátrica.

\section{MÉTODO}

O estudo teve como cenário a sala cirúrgica de um hospital geral, em Florianópolis, vinculado à Universidade Federal de Santa Catarina - UFSC. Foram sujeitos da pesquisa dez usuários, sendo três homens e sete mulheres, com faixa etária entre 26 e 60 anos, IMC entre 37,43 kg/m² e 62,20 kg/m², internados para realizar cirurgia bariátrica. Desses, nove estavam em préoperatório e um em pós-operatório. A coleta dos dados foi realizada em abril e maio de 2009. Para isso, utilizou-se a aplicação de um roteiro de entrevista semiestruturada. O projeto foi aprovado pelo Comitê de Ética de Pesquisa com Seres Humanos da UFSC. A análise dos dados constituiu-se em análise temática, sendo elaboradas duas categorias de análise: "o sujeito e sua família" e "como eu me vejo e como os outros me veem".

\section{RESULTADOS}

\section{O sujeito e sua família}

O arranjo familiar não tradicional é cada vez mais frequente. Um exemplo disso são as famílias monoparentais, sendo inúmeras as crianças vivendo com pais solteiros ou divorciados. Outro exemplo são os pais recasados, cujos filhos convivem ou não com o novo cônjuge do pai ou da mãe, e com os irmãos dessas novas uniões ou de uniões anteriores $^{(5)}$. Pelas entrevistas realizadas, observamos a interferência da família no desenvolvimento de cada componente da mesma.

[...]. Meu pai faleceu há 12 anos, mas a gente convivia muito bem, eu ia sempre à casa dele e ele vinha sempre na minha também, eu só não morei com ele... E com a mulher do meu pai me dou bem até hoje. (Débora)

É no seio da família que se desenvolve o aprendizado dos papéis que o indivíduo vai desempenhar no âmbito social, por isso a importância de compreender as relações e interações entre os membros da família(6).

As experiências dos sujeitos construídas na família, na escola, no bairro e em todos os seus círculos sociais contribuirão diretamente em sua formação enquanto adultos, tornandoos capazes de tomar decisões, relacionar-se, trabalhar, escolher um cônjuge ${ }^{(7)}$. Partindo disso, passamos para as cinco subcategorias analíticas: a história alimentar na infância; a história alimentar na adolescência e maturidade; o exemplo na família: obesidade é normal; relação com o parceiro: mudanças e limitações; e limitações do dia a dia.

\section{A história alimentar na infância}

Entendemos que a história de vida desses sujeitos do estudo pode ter influenciado no desenvolvimento dos respectivos quadros de obesidade mórbida. Sabe-se que a alimentação durante a infância, ao mesmo tempo que é importante para o crescimento e desenvolvimento, pode também representarum dos principaisfatores de prevenção de algumas doenças na fase adulta. Frequentemente, a família, os fatores sociais e os ambientais podem influenciar o padrão alimentar das crianças $^{(8)}$.

[...] A base da nossa alimentação era feijão, abóbora, batata, coisas mais pesadas. Meus pais sempre foram agricultores, então a mesa tinha comida muito variada [...]. Os doces eram minha mãe quem fazia, doces de frutas, mas nunca compravam doce de mercado, esses doces de hoje, industrializados, sabe? (Silvia)

A família exerce um papel nos hábitos alimentares das crianças, que também sofrem a influência de condições socioeconômicas e ambiente em que são criadas. Elas não possuem conhecimento quanto ao que é saudável e dispensável. Esse autocuidado, no entanto, se desenvolve nessa fase da vida das pessoas, com os exemplos presentes no dia a dia, partindo da relação interpessoal que mantêm, baseados no estilo de vida de cada família. A alimentação é um fator fundamental para a saúde da criança. Em razão disso, as práticas alimentares como práticas sociais precisam ser abordadas multidisciplinarmente, ultrapassando $o$ ato biológico ${ }^{(9)}$. A criança normalmente não decide o que vai comer, quando e onde. Ela aceita o que os pais decidem que é melhor para ela. A alimentação na infância também é citada pelos sujeitos como saudável, considerando a qualidade do alimento ingerido.

Ah, minha alimentação quando criança era saudável. [...] eu comia era arroz, feijão, batata, cenoura, beterraba... tudo que eu procuro dar para os meus filhos hoje. [...] não tinha fritura, [...] era mais galinha, maionese, macarrão. (Samanta)

Na promoção de uma alimentação saudável, os hábitos alimentares da idade adulta estão relacionados com os aprendidos na infância. $O$ adulto seleciona o que tem a sua disposição e utiliza o que pensa ser conveniente para proporcionar o cuidado mais adequado para os filhos, o que nos leva a refletir sobre possíveis julgamentos no que diz respeito à educação da criança. Antes de pensar em um desleixo 
na criação dos filhos, devemos nos remeter à educação desse adulto quando era criança, somado-se aí o estilo de vida que a família atual consegue manter, pois é nesse contexto social que o aprendizado para o cuidado da criança se formará.

O desejo de superalimentar o bebê ou os hábitos inadequados da família podem induzi-lo a "abandonar" a sua percepção fisiológica de saciedade, aceitando a saciedade do outro e não a própria. A afirmação "eu não preciso comer mais" é substituída pelo "não aguento comer mais"(10:2).

\section{A história alimentar na adolescência e maturidade}

Essa subcategoria trabalha a alimentação em duas fases da vida: adolescência e maturidade, abordando os hábitos alimentares e as mudanças adquiridas especialmente quando iniciam a adolescência.

A adolescência é uma etapa do desenvolvimento acompanhada de processos de crescimento e de maturação, tanto do ponto de vista somático quanto do psicológico. Trata-se de um período de elevada demanda nutricional, e, por esse motivo, a nutrição desempenha um papel importante no desenvolvimento do adolescente, uma vez que o consumo de uma dieta inadequada pode influenciar de forma desfavorável o crescimento somático ${ }^{(11: 512)}$.

Nafase adulta, as tendências de transição nutricional ocorridas em diferentes países convergem para uma dieta mais rica em gorduras de origem animal, açúcares e alimentos refinados e reduzida em carboidratos complexos e fibras. A isso se associa o declínio progressivo da atividade física, percebendo-se alterações na composição corporal, como o aumento da gordura corporal. No Brasil, estudos comprovam que essa transição nos padrões nutricionais, relacionando-os com mudanças demográficas, socioeconômicas e epidemiológicas ao longo do tempo, estão refletidas na diminuição progressiva da desnutrição e no aumento da obesidade(12).

Apresentamos a seguir os depoimentos dos sujeitos acerca da evolução de seus hábitos alimentares na adolescência e a evolução dos mesmos para a idade adulta.

Na minha adolescência mudou bastante, porque aí já veio o $X$-salada [...]. E também muda o controle da mãe sobre a comida da gente. [...] E também eu trabalhava, aí então vinha para a gente marmita pronta da própria empresa, e vinha muito aquele salitre [...]. Vinha comida normal, arroz, feijão, minestra, polenta, carne ensopada. (Samanta)

Após a independência financeira, as pessoas desenvolvem alterações em seus hábitos alimentares, com o acesso fácil a comidas industrializadas e práticas de serem preparadas. Além disso, os hábitos alimentares se adaptam aos ambientes a que pertencem os sujeitos e também às condições financeiras para mantê-los. Durante a adolescência, podem aparecer novos padrões e hábitos alimentares gerados por motivos psicológicos, sociais e socioeconômicos, incluindo a influência de amigos, busca de autonomia e identidade, aumento do poder de compra, hábito de preparar rotineiramente o próprio alimento, a urbanização e o hábito de comer fora de casa. Os adolescentes são vulneráveis pois tendem a omitir refeições, especialmente o café da manhã, e consumir mais alimentos entre as principais refeições, aumentando a ingestão de açúcares e gorduras saturadas e diminuindo a de micronutrientes ${ }^{(13)}$.

Não adianta dizer que eu tive alimentação saudável, sempre quis a partemais gorda, maismal passada da comida. Eeu sou gordo porque cozinho bem, faço lasanha, costela no forno. [...] (Jair)

Um aspecto a ser observado aqui é a importância da prática de educação em saúde para essas famílias, partindo mesmo das ações da enfermagem que abordem o tema da alimentação saudável. De acordo com a Teoria do Autocuidado, o adulto é responsável pelos que dele dependem, além de si mesmo(4). Daí a importância dos profissionais de saúde para ajudar no planejamento de uma dieta diária. Esses devem valorizar as preferências do sujeito em questão, relacionar os hábitos alimentares, a prática de escolha dos alimentos, o modo de preparo e o consumo às práticas de atividades físicas, além de pensar na nova rotina como algo a ser seguido em longo prazo ${ }^{(14)}$

\section{O exemplo na família - a obesidade é normal}

Sabe-se que exercício, dieta e genótipo interagem de modo complexo, e, por mais que se modifique o ambiente, os genes parecem ter um papel significante na determinação da longevidade, risco de doenças, potencial atlético e tendência à obesidade ${ }^{(15)}$. Os dados obtidos a partir da história de vida dos sujeitos do estudo indicam que muitos têm ou tinham familiares que também possuíam problemas com sobrepeso ou obesidade. Todas as minhas irmãs são gordas. [...] $A$ média de peso é de $100 \mathrm{~kg}$ para as mulheres.

Já entre os homens, o mais gordo deles pesa uns $80 \mathrm{~kg}$, e esse tem 1,75 $\mathrm{m}$ de altura. A média de altura entre a gente também vai de 1,60 $m$ a 1,75 $m$ de altura. Minha mãe [...] chegou a pesar uns 100 kg [...]. (Silvia)

O sobrepeso dos familiares é entendido como algo natural, parte da realidade em que os sujeitos do estudo vivenciam. A probabilidade genética de alguém ser obeso ou não depende de diversos fatores, entre eles a hereditariedade.

Estima-se que crianças cujos pais não sejam obesos tenham apenas $10 \%$ de chance de se tornarem obesas; se um dos pais for obeso, a chance é de $40 \%$, e chega a $80 \%$ para crianças com pai e mãe obesos. $\mathrm{O}$ ambiente tem papel decisivo no desenvolvimento da obesidade, não se sabendo bem como se dá a interação de fatores hereditários e ambientais no aumento de peso ${ }^{(16: 28)}$.

Observando que o fator genético influencia no desenvolvimento do sobrepeso ou obesidade, verifica-se como é importante que o autocuidado seja aprendido desde cedo. Dizemos isso pois tal criança crescerá e, com ela, seguirão os efeitos dos hábitos adquiridos, além de que servirá de exemplo a alguém futuramente. Sendo o autocuidado um conceito a ser construído, a motivação e o exemplo familiar são pontos fundamentais a serem tratados.

\section{Como eu me vejo e como os outros me veem}

Conviver em sociedade leva os indivíduos a criarem conceitos e imagens sobre pessoas, papéis, fenômenos do cotidiano, 
fundamentos para uma vivência baseada em representações entre os grupos sociais. Esses conceitos e imagens, naturalmente, são considerados certos ou errados. Um equívoco gerado na aceitação ou não de um desses conceitos pode provocar o surgimento do preconceito, do estigma e até mesmo de exclusões sociais ${ }^{(17: 23)}$. Nessa categoria do estudo, tratamos como o preconceito se faz presente na vida dos entrevistados e como os rótulos impostos pela sociedade influenciam em sua vida. Adjacente ao preconceito alheio, fizemos uma reflexão quanto à imagem que essas pessoas fazem de si.

\section{Autoimagem: espelho, espelho meu}

A imagem corporal é representada pelo que sentimos e pensamos sobre nossa aparência. Assim, a partir dela, a autoimagem é criada, com base em nossos valores e opiniões. A harmonia entre o que idealizamos e o que vemos diante do espelho é fundamental para levarumavida social adequada ${ }^{(18: 24)}$. Essa harmonia recebe influência do modo como essa pessoa age para alcançá-la, na maneira como ela cuida de si, nas atividades que desempenha visando a seu bemestar. No caso do indivíduo obeso, o descontentamento gerado pelo excesso de peso leva a uma autoimagem negativa. Como podemos observar nos depoimentos a seguir:

[...] Hoje eu não me olho no espelho. Antes

eu me olhava, me via magrinha e era muito

bom, agora eu não quero nem ver, passo

bem longe do espelho. [...] Antes eu gostava

do que eu via, hoje não gosto do que vejo. [...]

mas me aceito. (Samanta)

O fato de se olhar no espelho revela a

indignação e o questionamento pessoal quanto ao peso atual. $O$ sentimento de fracasso aparece e, por conseguinte, a vergonha em ver a própria imagem, mesmo estando sozinha, o que a leva a querer fugir de si mesma. A rejeição ao próprio corpo conduz à escolha de evitar ao máximo verem-se refletidas no espelho. Outro aspecto revelado está no fato de que todas as falas relacionadas à negação em se encarar diante do espelho são de mulheres. Estar fora do padrão de beleza aceitável socialmente mexe de forma mais significativa com a autoimagem e a autoestima feminina.

Outra questão analisada é a percepção real que o sujeito tem do próprio pesoe como issoéencaradoem seu dia a dia. A visão distorcida da imagem corporal pode agravar a qualidade de vida do obeso, uma vez que, não tendo as reais dimensões de seu corpo e da gravidade do excesso de peso em questão, o processo de conscientização e procura por ajuda especializada torna-se tardio, aumentando a probabilidade do desenvolvimento de comorbidades e de um abalo psicológico e da autoestima ${ }^{(19: 25)}$. Isso se reflete na fala de um de nossos entrevistados.

Semprefuiumrapazmuitoesportista, faziaauladecaratê, musculação, já cheguei a dançar no Clube das Mulheres, e hoje estando desse jeito [...] me sinto culpado de ser um rapaz tão atleta e do nada estar desse jeito, sabe, eu não senti que estava engordando, a impressão que me dá é que eu fui dormir com $74 \mathrm{~kg}$ e acordei com cento e poucos! [...] Talvez eu nem sinta que eu sou tão gordo assim, às vezes quando eu vejo uma pessoa gorda eu penso: "Poxa, que gordo, seráque eleémais gordo do que eu?", aí as pessoas falam: "Nossa, você é o dobro dele!", então pergunto: "Puxa, mas que tamanho eu tenho?". Assim, eu até consigo me visualizar, perceber a proporção em que eu estou gordo, sabe, uma vezou outra quando passo na frente do espelhoeumeolho, aípenso: "Puxa, estou gordo mesmo".[...] (André)

Talvez a autopercepção nesse caso esteja diretamente ligada a esse convívio, visto seu cotidiano ter se passado em ambientes frequentados por atletas, agravada pelo fato de que se tratava de um indivíduo que se manteve em perfeita forma física por longo período. Mesmo que, por motivos de relacionamento pessoal, tenha abandonado tal estilo de vida, sua autoimagem ainda permanece como se seu corpo fosse o mesmo de antes. Pensamos aqui na autodefesa decorrente da não-aceitação das mudanças em seu estilo de vida, que o deixavam feliz, fazendo com que André não se veja como obeso.

\section{Como os outros me percebem e me chamam}

Em tempos atuais, o conceito de estigma é utilizado para casos em que se salientam características ou sinais de falha, injustiça, infâmia, que causam vergonha ao indivíduo e tornam o mesmo indesejável, inferior e até ruim ou perigoso(20:26). Decorrente de ideias já fixadas, preconceitos estabelecidos com relação a determinado assunto ou sinal peculiar é que nascem essas espécies de rótulos que são atribuídos às pessoas que possuem esses sinais, estabelecendo classes ou categorias, desqualificando-as socialmente ${ }^{(17: 23)}$.

O estigma está diretamente ligado ao contexto das relações que tal sujeito mantém com sua sociedade e pode levar a um tratamento pejorativo. $\mathrm{Na}$ sociedade em que vivemos, é nítida a multiplicidade de estilos e personagens que compõem as populações de cada região do país, um contingente vasto de características individuais ${ }^{(21: 27)}$. Portanto, é de conhecimento geral que essas diferenças nem sempre são aceitas facilmente, visto que a sociedade é composta de uma elite, que, juntamente com a influência da mídia, por vezes, dita o que é certo ou errado o que se enquadra ou não nos padrões de vida por ela estabelecidos. Se um padrão de físico escultural predomina, indivíduos que não o alcançam terão seus valores negados em sua diferença, sendo alvo de preconceito e desvalorização de sua identidade (21:27). Os entrevistados desse estudo mostram com clareza e muito sofrimento o quanto se percebem excluídos do meio social pelo fato de serem obesos, conforme vemos a seguir.

[...] Hoje, seme perguntassem o porquê deeu quereroperar, ainda seria pelo preconceito das pessoas, pois hoje passo na rua e vejo as pessoas cochicharem: "Olha o tamanho dele, que gordo!" [...] Tem muita gente que diz que você é malandro, que é para fechar a boca. [...] No meu serviço [...]: "Pô, se você desse uma corridinha a mais na praia, talvez vocênão estivesse tão gordo" (André)

O preconceito faz parte do cotidiano do indivíduo obeso, e ele vem tanto de desconhecidos quanto de colegas de trabalho e até mesmo entre familiares, interferindo de fato em sua vida, em suas atitudes e decisões. Não ser "normal" Ihes causa sofrimento por si só, e esse sentimento os domina quando a informação sobre seu "defeito"é manipulada. Énessa hora que se 
percebe o dano causado à moral do sujeito obeso, do tamanho da violência que o rótulo de "pessoa relapsa" relacionado à imagem corporal lhes causa. A violência não necessariamente é evidenciada por marcas físicas; podemos avaliá-la como sendo também uma arma de repercussão psicológica, emocional, que atinge a autoestima.

Eu gosto muito de ir a festas, sabe, mas já desisti por causa do meu peso. Penso que se eu vou num lugar e vou ficar de mal comigo mesma, então prefiro nem ir. Acho ridículo ser gorda mesmo! Não vou mais nem à praia por causa disso. (Débora)

Outro aspecto relativo ao preconceito e estigma sofrido e percebido pelos sujeitos do estudo está no uso de termos pejorativos para designá-los, conforme referido por eles próprios.

[...] Claro que tem os que me chamam de baleião, hipopótamo, tudo quanto é bicho. [...] (João)

[...] Na família, eu acho que tem preconceito, sim. Jámechamaram de baleia, de gorda. Brincando ou não, chamam. (Débora)

Os apelidos ou termos pejorativos retratam ainda mais o estigma social enfrentado pelo obeso. Tal tratamento muitas vezes dá a impressão de que a identidade dessa pessoa é perdida, uma vez que os apelidos não raro tomam o lugar do nome próprio. $\mathrm{E}$, por mais que ele tente se acostumar com a situação, encarando-a como uma brincadeira, talvez o sofrimento de impotência por não ser considerado normal só o faça se esconder ainda mais da sociedade, atrasando o difícil processo do tratamento efetivo.

\section{CONSIDERAÇÕES FINAIS}

A escolha pela cirurgia bariátrica se insinua como uma forma de melhorar ou reduzir as limitações e desconfortos, considerando-se que todos os entrevistados relataram esse problema ao longo da vida. Além do sofrimento que a dor inflige, uma reflexão aqui se faz importante, pois ela não apenas dificulta a realização de atividades que antes faziam sem qualquer problema, mas por vezes traz a impossibilita até mesmo de tentar. Isso os leva, em alguns casos, a passarem pelo constrangimento pessoal de não conseguir realizar a própria higiene e chegar ao extremo de abandonar seus empregos. As dificuldades para o autocuidado devido aos limites decorrentes da obesidade influenciam também na não-realização de atividades físicas. O cuidado dos profissionais de saúde por meio de ações sistemáticas pode intervir positivamente no desenvolvimento do autocuidado.

Finalmente, podemos observar em cada indivíduo entrevistado um relato de vida diferente, com alterações psicoemocionais, hormonais, sociais e/ou econômicas que influenciaram o ganho de peso dos mesmos. O papel da equipe de saúde vai além de orientar e informar. Deve trabalhar com o objetivo de conscientizar o cliente a participar corretamente de seu tratamento, realizando educação em saúde de uma maneira simples, verdadeira, respeitando a capacidade intelectual e cultural de cada cliente.

\section{Referências}

1. Puglia CR. Indicações para o tratamento operatório da obesidade mórbida. Rev Assoc Med Bras. 2004;50(2):118.

2. Mariath $A B$. Obesidade e fatores de risco para o desenvolvimento de doenças crônicas não transmissíveis entre usuários de unidade de alimentação e nutrição. Cad Saúde Pública. 2007; 23(4):897-905.

3. Rosado EL, Monteiro JBR. Obesidade e a substituição de macronutrientes da dieta. Rev Nutr. 2001;14(2):145-52.

4. Torres GV, Davim RMB, Nóbrega MML. Aplicação do processo de enfermagem baseado na teoria de Orem: estudo de caso com uma adolescente grávida. Rev Latinoam Enferm. 2009;7(2):47-53.

5. Minella LS. Gênero e contracepção: uma perspectiva sociológica. Florianópolis: UFSC; 2005. p. 191.

6. Barros ML. Família e gerações. Rio de Janeiro: FGV; 2006. p. 163.

7. Wagner A, Falcke D, Meza EBD. Crenças e valores dos adolescentes acerca de família, casamento, separação e projetos de vida. Psicol Reflex Crit. 1997;10(1). 8. Rossi A, Moreira EAM, Rauen MS. Determinantes do comportamento alimentar: uma revisão com enfoque na família. Rev Nutr. 2008;21(6): 739-48.

9. Rotenberg S, De Vargas S. Práticas alimentares e o cuidado da saúde: da alimentação da criança à alimentação da família. Rev Bras Saúde Mater Infant. 2004;4(1):85-94.

10. Parizzi MR. A importância do resgate da percepção da saciedade no tratamento e na prevenção da obesidade da criança e do adolescente. Textos Cient Soc Mineira Pediatr. 2004.
11. Albano RD, Souza SB. Ingestão de energia e nutrientes por adolescentes de uma escola pública. J Pediatr. 2001;77(6).

12. Francischi RPP. Obesidade: atualização sobre sua etiologia, morbidade e tratamento. Rev Nutr. 2000;13(1):17-28.

13. Godoy FC. Índice de qualidade da dieta de adolescentes residentes no distrito do Butantã, município de São Paulo, Brasil. Rev Nutr. 2006;19(6):663-71. 14. Sebold LF, Radünz V, Rocha PK. Proenf: saúde do adulto. 2ª ed. Florianópolis: ABEn; 2007.

15. Bouchard C, Pérusse L, Rice T. The genetics of human obesity. In: Bray GA, Bouchard C, James WPT. Handbook of obesity. New York: Marcel Dekker; 1998. 16. Nahas MV. Atividade física, saúde e qualidade de vida. $4^{\mathrm{a}}$ ed. Londrina: Midiograf; 2006.

17. Rangel M. A violência do estigma e do preconceito à luz da representação social. Rev Bras Est Pedagog. 1993;74(178):639-54.

18. Pedrolo FT, Zago MMF. A imagem corporal alterada do laringectomizado: resignação com a condição. Rev Bras Cancerol. 2000;46(4):407-15.

19. Nascimento LMP, Amaral RM, Menezes RL. Percepção da imagem corporal, autoestima e qualidade de vida em alunos da Unati/UCG. Rev Digital EFDeportes. 2008;14(127).

20. Schillng F, Miyashiro SG. Como incluir? O debate sobre o preconceito e o estigma na atualidade. Educ Pesqui. 2008;34(2):243-54.

21. Bandeira L, Batista AS. Preconceito e discriminação como expressões de violência. Rev Estud Feminista. 2002;10(1):119-41. 